\title{
Research and Design of Lightning Protection System for Oil Tanks
}

\author{
C Zhou ${ }^{1, *}, \mathrm{X} \mathrm{Cao}^{2}, \mathrm{Y} \mathrm{Li}^{3}$ and $\mathrm{J} \mathrm{Wang}^{4}$ \\ ${ }^{1}$ School of Information Technology and Electrical Engineering, The University of Queensland, St Lucia, QLD, 4072, Australia \\ ${ }^{2}$ School of Petroleum Engineering, Northeast Petroleum University, Daqing, HLJ 163318, China \\ ${ }^{3}$ Liaohe Oilfield Information Engineering Co. LTD. No. 78, Oil street, Xinglongtai District, Panjin, Liaoning, 124010, China \\ ${ }^{4}$ Heilongjiang Provincial Key Laboratory of Oil and Gas Reservoir Stimulation, Production Technology Institute of Daqing Oilfiled Co. Ltd., Daqing, \\ Heilongjiang, 163453, China
}

\begin{abstract}
The construction of large oil depots has become increasingly important, and oil storage safety also becomes a hot topic. It can be seen from multiple major safety accidents that have occurred in recent years that lightning is considered being one of the main causes of oil tank fires. Through in-depth research on safety issues, we are trying to find a scientific and economical safety management model for oil depots. Most of the objects stored in the oil depots are flammable liquids, and the oil gases which are produced by oil products can easily cause an explosion. A little carelessness may cause casualties and huge economic losses. The main purpose of this research is to design a lightning protection system for fixed roof oil tanks on the ground. By providing a complete design of lightning protection, to show how to ensure the safety level of the oil tank and oil depots, then the authors briefly describe other latest technologies for lightning protection which could be used in the future improvement.
\end{abstract}

\section{Introduction}

Because of global climate change, the frequency of accidents which include equipment damage and fire damage caused by lightning in fuel depots is rapidly increasing. In July 2001, a large-scale tank fire accident occurred at the Orion Noroo Oil refinery in the United States. Lightning struck a floating roof tank with a diameter of 80 meters and stored 300,000 barrels of fuel oil, which immediately caused a fire [1]. As a result, the tank was completely destroyed. According to the Journal of Hazardous Materials [2], in the 20 accidents involving products tanks, 16 of them were caused by lightning strokes, so it is necessary to design a reliable lightning protection system for oil tanks and fuel depots.

Implementing lightning protecting facilities in fuel depots requires corresponding standards and specifications. The relevant standards in China are mainly "Code for Lightning Safety of Oil and Petroleum Facilities", "Code for Fire Protection of Petroleum and Natural Gas Engineering Design", "Code for Design of Petroleum Depots", etc. Although there are effective lightning protection standards as a reference and we can follow these specifications to build a lightning protection system, the probability of fire caused by lightning is still very high. Hence, the work of lightning protection and fire protection still need to be further studied.

\section{Lighting and lightning protection}

\subsection{Lightning}

Lightning is a natural climatic phenomenon common in our lives. Under certain conditions, we can regard them as a natural disaster with strong destructive power. The economic losses caused by lightning can reach tens of billions worldwide every year [1]. In August 2006, a fire broke out at an oil tank in a Chinese oil transmission station, the reason of the fire was a lightning strike, and the oil tank was a floating roof tank [3]. The oil gas concentration in the sealed space was greater than the standard, the primary seal and secondary seal of the tank were completely destroyed, and the flame when burning was up to 10 meters. A similar accident occurred in July 2007. Lightning can cause direct lightning damage, indirect lightning damage, lightning wave intrusion hazards, and the causes of damage are many, and the damage will cause harm from multiple aspects.

\subsection{Lighting protection technologies}

Combustibles, fire source, and combustion-supporting materials are the three elements of ignition. In the production of products, we cannot remove combustibles. Therefore, we trying to prevent products from 'fire source'. The basic measures to eliminate the possibility of fire caused by lightning are: clear the lightning arc and reduce the probability of generating this fire source, to reduce the

\footnotetext{
Corresponding author: chengyu.zhou@uq.net.au
} 
potential fire hazard. Western countries have relatively advanced technologies to lightning protecting, they mainly include telescopic grounding devices, improved floating roof sealing technology, etc [4].

After the 1980s, GPS systems and high-speed processing technology for big data have been implemented in lightning protection research. With the application of high-temporal resolution detection technology in lightning monitoring, there was an opportunity to study the microsecond and sub-microsecond lightning processes. Since then, active lightning protection system technology has been developed. Kaihua Jiang [5] and Lin Du with their colleagues proposed a non-contact multi-physical parameter lightning monitoring system, which can identify 6 types of direct lightning strokes. If this technology be implemented worldwide, we will no longer limited by traditional passive lightning protection. The novel technology like the example above can also effectively avoid the indirect damage from lightning to the building.

\subsection{Protection technologies for different tanks}

Different oil tanks catch fire differently after being struck by lightning. Hence, we need different lightning protection systems to achieve adequate lightning protection. For earthcovered oil tanks, the soil has a certain shielding effect, so when the buried depth reaches the standard, the soil will sufficient to protect the oil tank. Above-ground floating roof oil tanks are divided into external floating roof tanks and internal floating roof tanks, there is a great demand for grounding facilities for floating roof tanks. The external floating roof tanks are relatively safe because the air space above the oil tank is almost zero. For instance, in the experiment processed by Xiaoming Ren [6] and his team, the tank shell of the tank they tested can be used as a lightning rod, and then they achieved comprehensive lightning protection for tanks by using multiple scalable grounding device (SGD). For the internal floating roof tank, it not only needs to concentrate on grounding but also needs to be concerned about the density of oil gas on top of the tank.

For the non-metallic oil tanks and metal fixed roof oil tanks, both of them need to add lightning rods to ensure the lightning protection. Non-metallic oil tanks should establish independent lightning rods to protect themselves during lightning strikes, and electrical connections need be installed on external metal accessories. When the thickness of the top plate is more than $4 \mathrm{~mm}$, there is no need to set a lightning rod for the metal fixed top oil tank (according to Design Specification for Oil Depot GBJ74-84). Considering various unavoidable negative factors, such as steel plate corrosion and uneven material, it is determined that when the top plate is less than $4 \mathrm{~mm}$, a lightning rod needs to be set up. The protection ranges should include the entire oil tank, and the protection ranges should be at least $2 \mathrm{~m}$ higher than the breathing valve.

In China, metal oil tanks are widely used, and internal floating roof oil tanks are often used to store volatile light oil products. Although the metal oil tank itself has a certain protection effect, the lightning protection cannot be negligent for this reason. In addition, lightning rods for fixed roof oil tanks require rigorous calculations. Therefore, it is especially important to understand the lightning rod and calculate the protective range of the lightning rod.

\subsection{Lightning rods}

The principle is to keep the lightning rods closest to the thundercloud. The lightning rod has good conductivity, and it can generate the opposite electric charge with thunder through induction effects [7]. Hence, when thundercloud releases lightning, it will enter from the lightning rod instead of entering directly from the building. Then, energy from lightning will be transported to the ground through the predetermined route of the conductive grounding system.

\subsection{The range of protection}

Different lightning rod combinations have different protection range. The lightning rod can not only protect the building itself but also the space around the lightning rod. There are many ways that lightning strikes a building, and it is difficult fully protect a space from lightning strikes. It is worth mentioning that protected area should not be as large as possible. If the protection range is large and not concentrated, the oil tank will be more likely to be penetrated by lightning strikes.

Protection range of a single lightning rod is relatively small. A single lightning rod can protect a single oil tank or a small oil tank. The developer can set up an independent lightning rod or set up a lightning rod on the tank top. The protection scope is similar with a tent [8].

Protection range of two lightning rods is looks like the back of a camel [1], as shown in figure 1 .

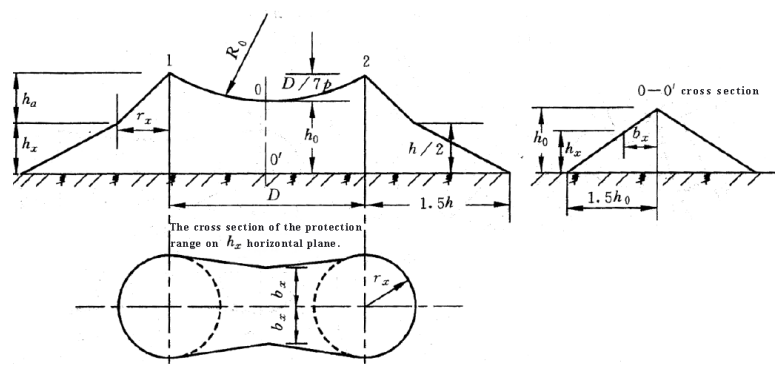

Figure 1. Protection range formed by two lightning rods with equal height [1].

The minimum width of the protection range between two lightning rods on a horizontal surface of $h_{x}$ is $2 b_{x}$.

The distance between the lightning rods should smaller than $7 \mathrm{~h}_{a} P$.

The precise value may be determined according to the following equation[1]:

$$
\left(\frac{b_{\mathrm{x}}}{r_{\mathrm{x}}}\right)^{1.4}+\left(\frac{a}{7 h_{\mathrm{a}} P}\right)^{1.3}=1
$$

$b_{x}$ - Protection width on both sides of the centreline of two lightning rods, $\mathrm{m}$. 
$a$ - Distance between two lightning rods, $\mathrm{m}$;

$h_{a}$-Effective height of lightning $\operatorname{rod} h_{a}=h-h_{x}$, $\mathrm{m}$;

$r_{x}$ - Protection radius of lightning rod at height, $\mathrm{m}$;

$P \quad$-When the lightning rod exceeds $30 \mathrm{~m}$, the protection range is affected by the height.

If $h \leq 30 \mathrm{~m}, P=1$. if $30<h<120 \mathrm{~m}, P=$

$\left(\frac{30}{h}\right)^{1 / 2}=\frac{5.5}{\sqrt{h}}$.

The symbol $h$ is the total height of the lightning rod which is counted from the ground, $\mathrm{m}^{[1]}$

The shape of the protection range of three equal height lightning rods on a horizontal surface of $h_{x}$ is similar with a triangle. As shown in figure 2 .

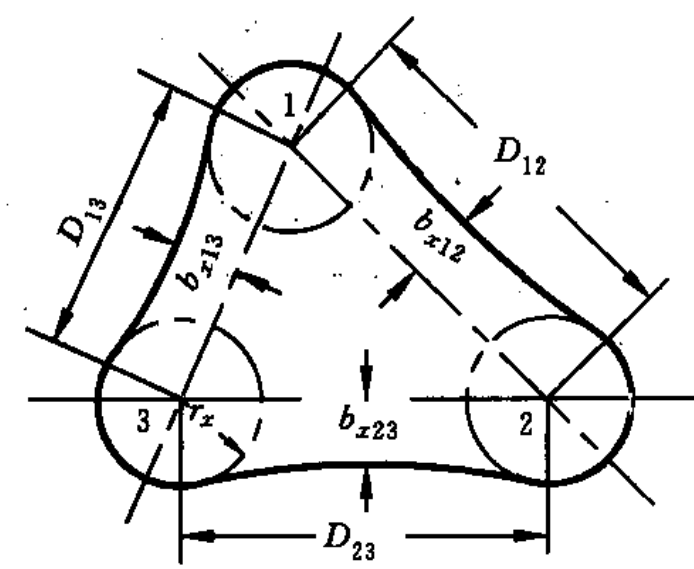

Figure 2. Protection range formed by three lightning rods with equal height [1].

For the polygon formed by four or more equal lightning rods can be split into multiple triangles, and then the protection range of four or more lightning rods can be calculated by using the method of calculating triangle protection range [9].

At this moment, the conditions for protecting the entire area are:

$$
D \leq 8 h_{\mathrm{a}} P
$$

$D$ - the diameter of the circumscribed circle of a triangle with an approximate protection range for three lightning rods. It also represents the long diagonal of a polygon formed by the protection range for four or more equal height lightning rods [1].

\subsection{The installation and use of the lightning protection device}

The complete lightning protection device comprises the airtermination device, the down lead, and the earthing device [10], as shown in Figure 3. Reasonable installation and timely maintenance of the protection device are the basis for ensuring the safety and stability of oil depots.

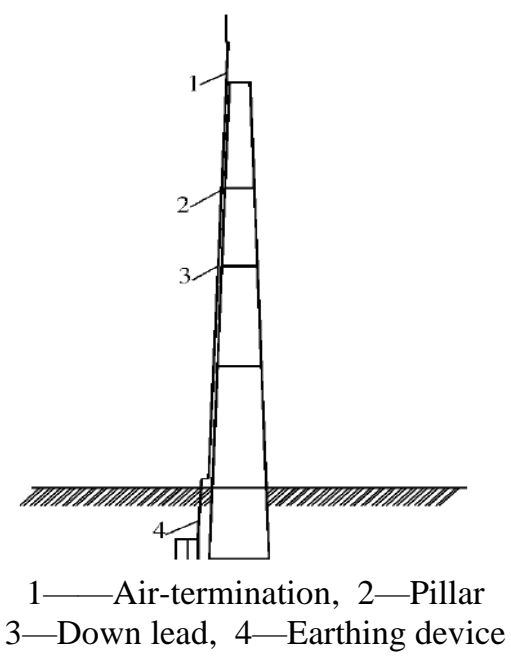

Figure 3. Schematic diagram of lightning arrester structure [1].

\section{Design of lightning protection equipment for crude oil depots}

\subsection{Floating root flexible seal}

Most floating roof oil tanks still use mechanical seals, but it is easy to accumulate a large amount of explosive oil gas between the primary seal and the secondary seal. Therefore, from a safety point of view, the mechanical seal should be changed to a flexible seal structure. Moreover, secondary flexible sealing should use conductive materials, so that lightning can be led out in time [11].

This sealing technology can reduce the concentration of oil gas between the sealed space, and also avoid the metal protrusions, which can effectively reduce the possibility of explosions caused by electric sparks in the oil gas space.

Although this technology has many benefits, it also has drawbacks. The sealing effect weakens with time and needs to be checked and replaced regularly.

\subsection{Multi-directional lightning protection grounding and equipotential bonding}

According to relevant standards and regulations, the tank shell earthing device should be connected to the depot earthing device with more than two connection points, and the device should use materials with good electrical conductivity and corrosion resistance.

Regarding equipotential bonding, the main problems are: the corrosion of the wires connecting the floating plate and the tank shell and the occurrence of poor contact will increase the impedance ${ }^{[11]}$. According to the relevant standards and specifications, at least two twisted pairs are required to connect the floating plate and the tank shell, the cross-sectional area of each pair should at least $50 \mathrm{~mm}^{2}$.

In addition to the above connections, grounding and equipotential bonding must be considered at other parts of the oil tank, such as between the escalator and the tank shell, and between the escalator and the floating plate. Similarly, developers and engineers should think monitoring the facility as a part of the equipotential bonding. 


\section{Design of lightning protection device for oil tank}

\subsection{Tank data and lightning requirement}

The volume of exampled fixed roof oil tank on the ground in this case is $4832 \mathrm{~m}^{3}$ (nearly $5000 \mathrm{~m}^{3}$ ), the height of the tank is $11.845 \mathrm{~m}$, the height of the tank roof is $0.57 \mathrm{~m}$, the diameter of the tank is $22.79 \mathrm{~m}$, and the thickness of the roof is $3 \mathrm{~mm}$. There is a flame arrester. Because the tank itself is made of metal and has conductivity, there is no need to set down leads, and the protection range is at least $2 \mathrm{~m}$ higher than the breathing valve. For this fixed roof metal tanks with fire arresters on the ground, a lightning rod needs to be installed for lightning protection when the thickness of the roof is less than $4 \mathrm{~mm}$. Table 1 shows the lightning rods and grounding requirement for oil tanks with different volume. The specification states that the drift resistance of the groundings must not exceed $10 \mathrm{ohms}$ [1].

Table 1. Number of lightning rods and groundings for common oil tanks [1].

\begin{tabular}{lllll}
\hline Volume of & 100 & $\begin{array}{l}1000- \\
\text { tanks }\end{array}$ & $\begin{array}{l}\text { - } \\
700\end{array}$ & $5000 \mathrm{~m}^{3}$ \\
& $\mathrm{~m}^{3}$ & & \\
\hline $\begin{array}{l}\text { Number of } \\
\text { lightning } \\
\text { rods }\end{array}$ & 1 & 3 & 4 \\
$\begin{array}{l}\text { Number of } \\
\text { groundings }\end{array}$ & 2 & 3 & 4 \\
\hline
\end{tabular}

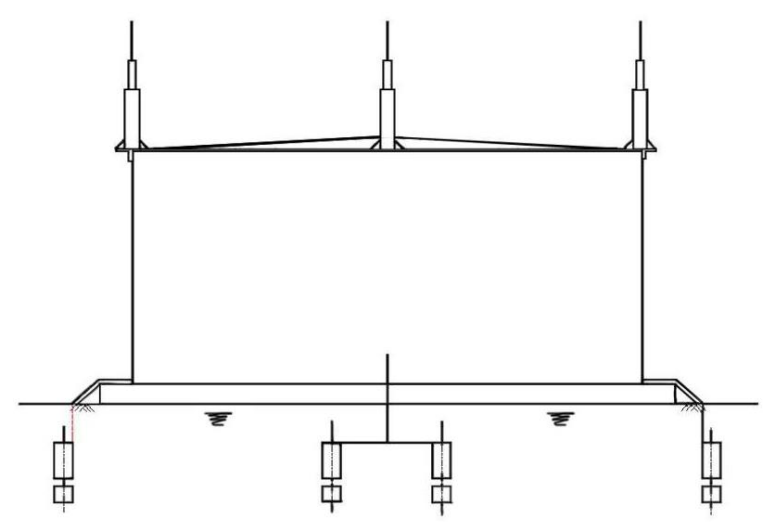

Figure 4. The front view of lightning protection device for fixed roof oil tank.

Hence, this design should use with 4 lightning rods and 4 groundings, the protection range of the lightning rod needs to include the entire oil tank, and the protection height is at least 2 meters higher than the breathing valve, and the grounding point is not less than 2 . The grounding point of this design is 3 , and the drift resistance value is $10 \mathrm{ohms}$.
According to the above requirements and data, design the lightning protection device. The arrangement of lightning rods and groundings is shown in figure 4 . There are two lightning rods in the middle of the top of the tank, which are placed on the edge of the tank. Since this image is showing the front view of the design, the two lightning rods overlap each other.

\subsection{Structure data of lightning protection equipment}

The material of lightning rods is generally one of galvanised steel strip and flat sealed galvanised steel pipe. To decide which one is selected as the material depends on the specific construction conditions. We should select the material that is relatively easy to obtain. In this design, the authors use galvanised steel pipe which the diameter is $25 \mathrm{~mm}$.

For groundings, we select the composite grounding for this tank. It comprises four vertical groundings. The length of each single grounding is 3 meters. The buried requirement is not less than 0.5-0.8 meters. Hence, authors decide to take 1 meter, the material is composed of over two angle irons, steel strips or steel pipes.

\section{$5 \quad$ Methodology}

\subsection{Drift resistance}

Grounding lightning grounding device is a composite, the drift resistance of composite grounding equation ${ }^{[1]}$ :

$$
R_{\mathrm{i}}=\frac{R}{n \eta}
$$

$R_{\mathrm{i}}$ Drift resistance of the composite grounding, kilohms

$R$-Drift resistance of a single vertical grounding, thousand ohms;

$n$-The number and root of the vertical grounding;

$\eta$ - the shielding factor of the composite grounding. Generally, take 0.8 .

According to the formula above, the author assuming the drift resistance of composite grounding of $10 \mathrm{ohms}$, then we can get $R=32$ ohms. it can be known that if the drift resistance value of the composite grounding body is less than $10 \mathrm{ohms}$, it is necessary to ensure $R<32 \mathrm{ohms}$. This experiment takes $20 \mathrm{ohms}$, and the drift resistance of the composite grounding is $6.25 \mathrm{ohms}$.

\subsection{Determine the conditions for comprehensive lightning protection}

In this design, four lightning rods are evenly distributed around the edge of the tank roof. It can be seen that the interval between adjacent lightning rods is $16 \mathrm{~m}$ (which means $a=16 \mathrm{~m}$ ). The condition that four lightning rods can protect the entire area is that the long diagonal $D$ of the quadrilateral meets (3).

According to equation (2), we assume $h \leq 30 \mathrm{~m}$, so $P=1$. 
Then, we can get $h_{a} \geq 2.27875 m$ (The height of the tank top has been subtracted.) as in equation (3) and $h \geq$ $14.12375 m$ obtained.

It can be known from the calculation that the height of lightning rods (counted from the ground) can be selected between $14.12375-30 \mathrm{~m}$, so $18.345 \mathrm{~m}$ is taken in this design. The height of the lightning rod itself is $6.5 \mathrm{~m}$.

After simulating the data above, authors confirmed that such a design meets the needs of protecting the entire tank area.

\subsection{Results}

To ensure that the above calculations meet the relevant oil depot and tank lightning protection standards, the authors conducted multiple tests on the data under the "Code for Design of Lightning Protection of Buildings" and "Code for Lightning Safety of Petroleum and Petroleum Facilities".

The design of the grounding device which is included in the design of the lightning protection device were mainly checked. However, since the welding quality and other conditions cannot be accurately determined under simulation conditions, all inspections were performed on the assumption that there was no problem with welding. The results are organised as Table 2 .

Table 2. Table of design data of lightning protection devices for the fixed roof metal oil tank

\begin{tabular}{|c|c|c|c|}
\hline Name & Value & Name & Value \\
\hline Tank capacity & $4832 \mathrm{~m}^{3}$ & Tank height & $\begin{array}{l}11.845 \\
\mathrm{~m}\end{array}$ \\
\hline $\begin{array}{l}\text { Diameter of the } \\
\text { tank }\end{array}$ & $22.79 m$ & Tank top height & $0.57 \mathrm{~m}$ \\
\hline $\begin{array}{l}\text { Number of } \\
\text { lightning rods }\end{array}$ & 4 & $\begin{array}{l}\text { Number of } \\
\text { groundings }\end{array}$ & 4 \\
\hline $\begin{array}{l}\text { Height of } \\
\text { lightning rod } \\
\text { (from tank top) }\end{array}$ & $6.5 \mathrm{~m}$ & $\begin{array}{l}\text { Drift resistance of } \\
\text { a single } \\
\text { grounding }\end{array}$ & $20 \Omega$ \\
\hline $\begin{array}{l}\text { Distance } \\
\text { between two } \\
\text { lightning rods }\end{array}$ & $16 \mathrm{~m}$ & $\begin{array}{l}\text { Drift resistance of } \\
\text { composite } \\
\text { grounding }\end{array}$ & $6.25 \Omega$ \\
\hline $\begin{array}{l}\text { Grounding's } \\
\text { buried depth }\end{array}$ & $1 \mathrm{~m}$ & $\begin{array}{l}\text { Length of single } \\
\text { grounding }\end{array}$ & $3 m$ \\
\hline
\end{tabular}

\section{Summary}

Society increasingly depends on petroleum products, so storage management of crude oil and its products has become particularly important. Lightning protection is an indispensable part of the oil depot safety system. This paper mainly introduces the lightning protection of oil tanks, and by designing a lightning protection system for an aboveground fixed roof metal tank, providing some ideas for the construction of the lightning protection device. Although there are various emerging technologies, we still cannot say that the threat of lightning to the oil depot can be completely eliminated. Further improvement of the lightning protection device is necessary. There are many non-traditional lightning rods that can be used, such as early streamer emission lightning rods (ESE), and the grounding system has also been improved, but there are still some doubts about these technologies. We still need to continue to explore how these technologies will perform in a largescale oil depot.

\section{References}

1. Guo G, Dong W and Zhang Z 1991 Oil Depot Design and Management. University of Petroleum Press 991.

2. Journal of hazardous materials 1976 Journal of hazardous materials

3. Ding B 2016 Research on the status of primary and secondary sealed lightning protection technology for floating roof oil tanks $\mathbf{4 4}(1): 38-40$

4. Li J and Liu Y 2012 Reflections on Lightning Protection Technology for Oil Storage Tanks China Petroleum and Chemical Standards and Quality. 32:48

5. Jiang K, Du L, Chen H, Yang F and Wang YJE 2019 Non-Contact Measurement and Polarity Discrimination-Based Identification Method for Direct Lightning Strokes 12(2):263.

6. Ren X, Fu Z, Yan N and Sun W 2013 Analysis and Experimental Investigation of Direct Lightning Protection for Floating Roof Oil Tanks Electric Power Systems Research. 94:134139.

7. Wang C and Zou Y 2009190 Questions for Lightning Protection for Electrical Grounding Shanghai Science and Technology Press

8. Wang X, Zhu H and Shi Y 2006 Electrical Safety Explosion-proof Technology of Oil Depot China Electric Power Press.

9. He T, Zhong J and Yang J 2007 Discussion on Lightning Protection of Substations China Petroleum and Chemical Standards and Quality. 32:05

10. Liang C and Xu G 2010 Talk About the Causes and Countermeasures That Affect the Reduction of the Lightning Rod Grounding Resistance Popular technology. pp 105-106.

11. Zhou Y, Zhao X, Pan S and Ling J 2012 Comprehensive Lightning Protection for Large Storage Tanks in Oil Depots Petroleum Engineering Construction. 38(1):5$9+83$ 